\title{
Sudanophil leucodystrophy: a study of inter-sib variation in the form taken by the demyelinating process
}

\author{
R. M. NORMAN, the late A. H. TINGEY, J. C. VAlEnTINE, AND \\ H. J. HISLOP \\ From the Burden Neuropathological Laboratory, Frenchay Hospital, Bristol, The Bedford General Hospital, \\ and the Bromham Hospital, Bedford
}

In 1962 Norman, Tingey, Valentine, and Danby reported the case of a 3-year-old microcephalic and paraplegic boy whose brain showed pachygyria, cerebellar atrophy, and sudanophil leucodystrophy. This patient had an elder sister whose physical appearance and neurological signs were so similar that it was evident that at least certain features of this complex condition had been inherited. This girl has now died at the age of 11 years and is the subject of the present paper. The two sibs showed remarkable differences in the form taken by the demyelinating process and we believe that these findings are relevant to current problems concerning the classification of leucodystrophies of sudanophil type.

\section{CASE REPORT}

CLINICAL HISTORY A.R.W., a girl, was the first born child of healthy parents. She was admitted to Bromham Hospital at the age of 2 years and was found to be a microcephalic idiot (head circumference $15 \frac{1}{4}$ in.). She bore a striking resemblance to her younger brother (the subject of the previous report in 1962), having curly ginger hair, sharp features, and long, tapering fingers. Her chest was peculiarly shaped, the nipples being high and the lower ribs protuberant. She was unable to sit without support and both legs were spastic in extension and adduction. The upper limbs were less stiff but she was never able to use them to any purpose. There was convergent strabismus and nystagmoid movements of the eyes. The optic discs and fundi were normal.

At 6 years of age her head circumference was 16 in., height $3 \mathrm{ft}$. 1 in., weight $29 \mathrm{lb}$. She was affectionate and sought attention, seeming to recognize her relatives and certain nurses whom she welcomed with a smile. She survived measles, rubella, infectious hepatitis, mumps, and a fractured femur which united satisfactorily. During the last year of her life she began to have difficulty in feeding, developed a urinary infection and deteriorated, slowly at first but more rapidly during the last four months when she lay helplessly staring at the ceiling. She died in an emaciated condition at the age of 11 years.
NECROPSY Death was due to bronchopneumonia. There was mild cylindrical bronchiectasis in the lower lobe of the right lung. There were no foam cells in the pulmonary alveoli (as had been seen in her brother). The uterus was rudimentary and the tubes and ovaries were not found. The cranial cavity was considerably reduced in size, the dura mater normal, and the brain showed a simplified gyral pattern. A detailed necropsy revealed no other significant abnormality. Microscopically, the only unusual findings outside the nervous system were intimal thickening and elastic tissue hyperplasia of the coronary arteries, and periductal lymphocytic infiltration in a salivary gland without cytomegalic inclusions.

\section{STUDY OF THE CENTRAL NERVOUS SYSTEM}

MACROSCOPIC The brain weighed 377 g., the cerebellum and brain-stem contributing $56 \mathrm{~g}$. In each frontal lobe there were shallow sulci running sagittally and more clearly defined on the right side where three main frontal gyri were present (Fig. 1). The postcentral gyrus was well demarcated. There were no interparietal sulci and the direction taken by the shallow sulci in the parietal region were in the direction of the Sylvian fissure. Both parietooccipital fissures were carried over for a considerable distance on the convexity. The temporal lobes were asymmetrical and the configuration of the sulci was irregular (Fig. 2). Here and there, some shallow bossing of the gyral surfaces was seen. The inferior surface of the brain was unremarkable, as were the vessels and cranial nerves. On the medial surfaces the cingulate gyri and calcarine fissures were identified and a thin corpus callosum was present. The cerebellum showed no gross malformation but its consistency was abnormally dense and the lateral lobes splayed out so that the inferior vermis was unduly visible. On sectioning the cerebral hemispheres, it was seen that parts of the cortex in the frontal cortex were abnormally thick and that 
the white matter was reduced in depth with enlargement of the lateral ventricles (Figs. 2 and 3). In the frontal and occipital poles, there was a patchy discoloration of the white matter suggesting demyelination.

MICROSCOPIC Representative areas of the brain were studied in large celloidin and frozen sections stained for nerve cells, myelin, axis cylinders, fibrous glia, and lipid.

Changes in the cerebral white matter Axis cylinders were normally present in all parts of the brain (Fig. 5b) and the changes in the myelin sheaths to be described represent demyelination in the strict sense. Large parts of the hemispheric white matter stained poorly for myelin, particularly the gyral cores which peripherally were sometimes severely demyelinated (Figs. 3 and 4). The body of the corpus callosum stained well at some levels, but elsewhere often showed a patchy loss of myelin in its ventral part. The anterior part of the left frontal lobe contained a large focus of demyelinated tissue occupying the lateral and ventral walls of the ventricle (Fig. 5a). The margin was vaguely demarcated and patches of better preserved fibres gave a coarsely mottled appearance to the area. On the right side a section taken at a more anterior level showed a slighter myelin loss in the same localization. In the occipital lobes there was conspicuous, patchy demyelination, vaguely demarcated from a background generally poor in myelinated fibres. Greatly dilated perivascular spaces gave a fenestrated appearance to many parts of the white matter (Fig. 6).

The myelin sheaths in the cerebral cortex were often entirely absent over large areas or were partially preserved in a discontinuous way, as in the stria of Gennari. In parts of the malformed cortex a remarkable mottled appearance was given by the patchy degeneration of the myelin, the preserved fibres being particularly well myelinated (Fig. 6).

In the basal ganglia the compact fibre bundles of the putamina and caudate nuclei were completely demyelinated. Each globus pallidus stained a uniform grey in myelin stains (Fig. 3). The thalami were much better myelinated and gave a normal impression except that patches of almost complete myelin loss, roughly symmetrical on the two sides, were seen at the margins of the medial nucleus (Figs. 4 and 7).

The internal capsules were well myelinated. Both optic tracts contained central areas of myelin pallor.

Brain-stem A patchy, discontinuous type of demyelination was a conspicuous feature of the tegmentum of the otherwise well-stained mid-brain and pons (Figs. 8a and b). The medulla was much

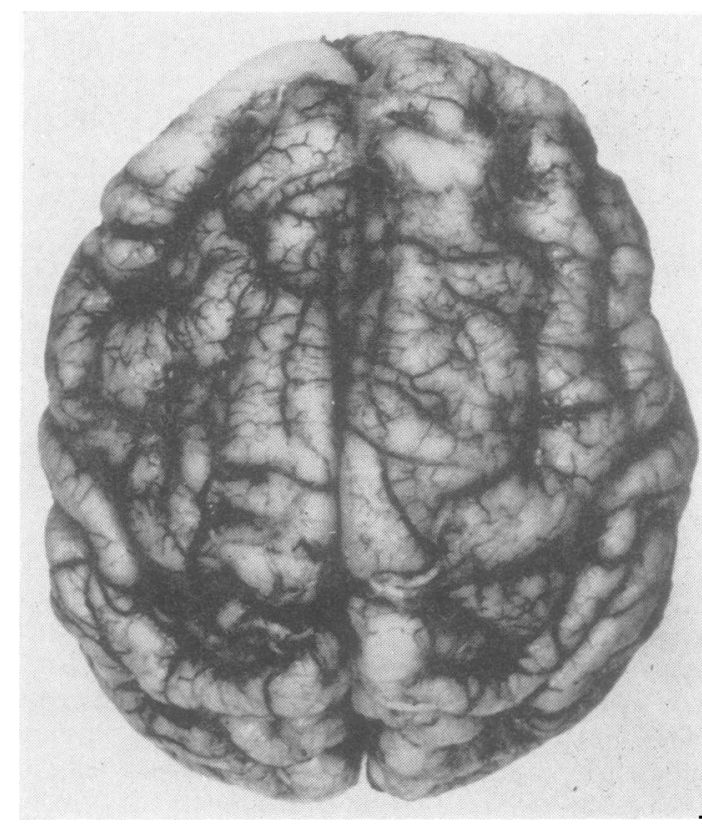

FIG. 1. Frontal lobes showing broad, irregular coßู जे volutions.

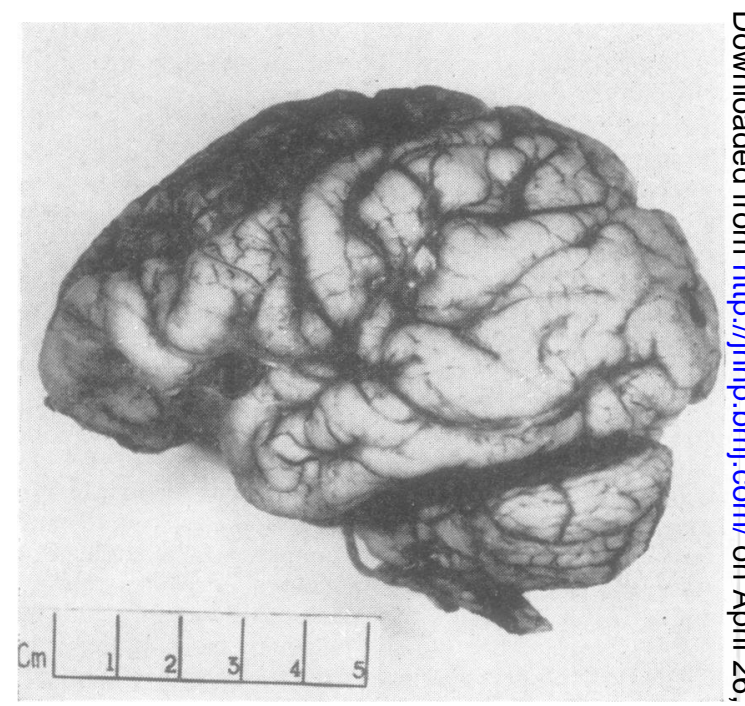

FIG. 2. Lateral view of left cerebral hemisphere showing abnormal gyral pattern of the temporal and parietal lobes. 


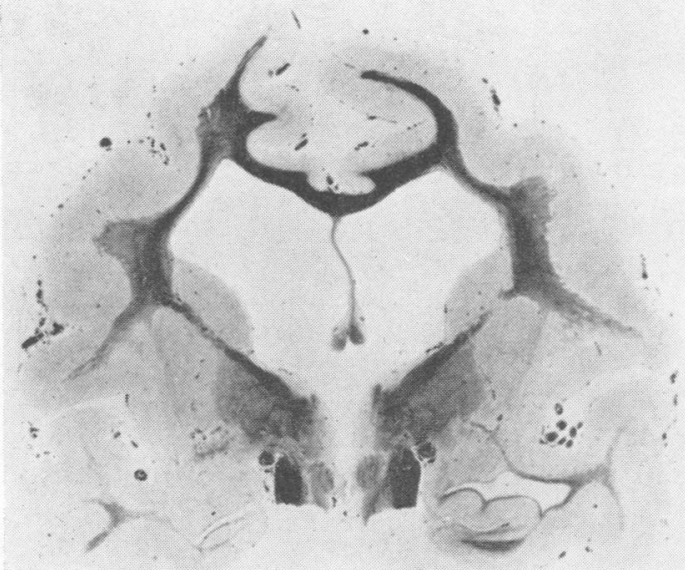

FIG. 3. Coronal section showing increased depth of parts of the frontal grey matter, reduced extent of the centrum ovale, and diffuse pallor of much of the white matter. Heidenhain $\times 1$.

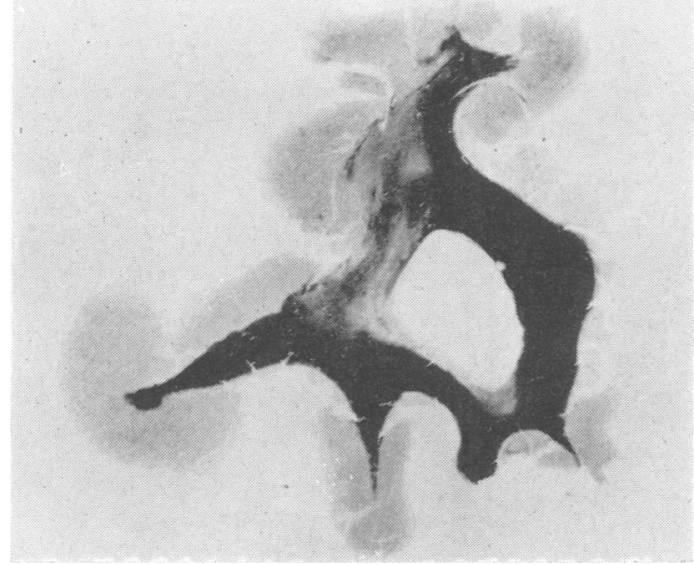

FIG. 5a. Left frontal pole showing discontinuous demyelination. Kultschitsky-Pal $\times 1 \cdot 6$.

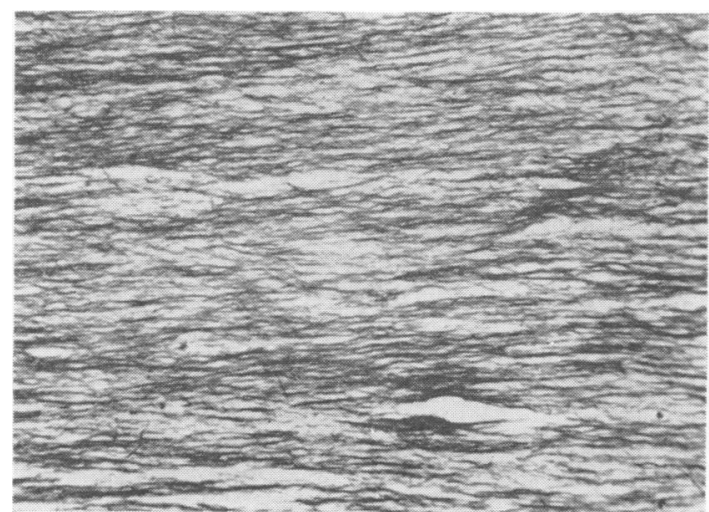

FIG. 5b. Preserved axis cylinders in a severely demyelinated patch (corresponding section to Fig. 5a). GrosBielschowsky $\times 440$.

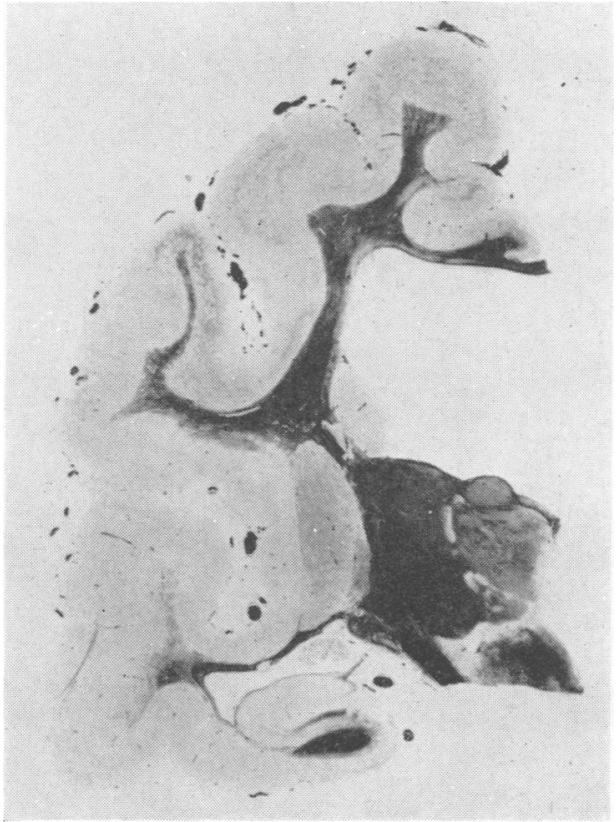

FIG. 4. Coronal section of left hemisphere at midthalamic level showing focal accentuation of the demyelination in the corpus callosum, lateral parts of the medial thalamic nucleus, and midbrain. Heidenhain $\times 1 \cdot 5$.

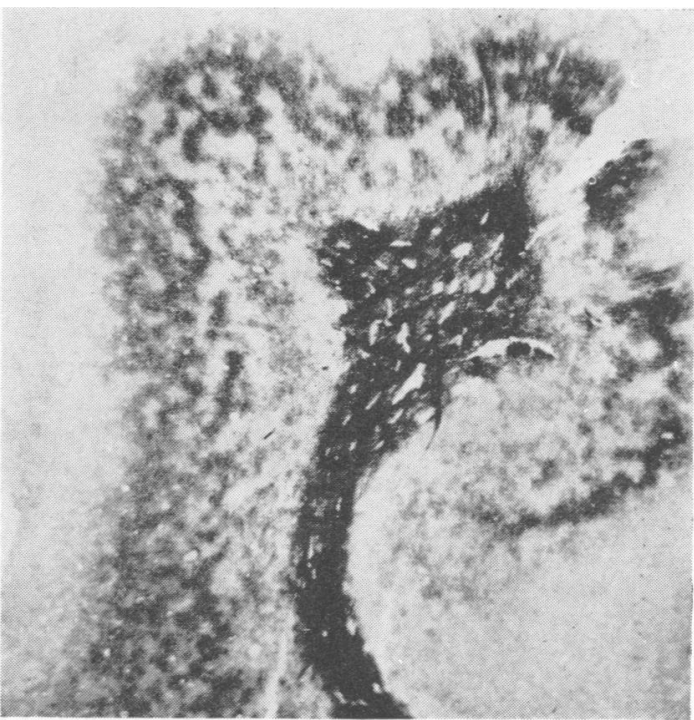

FIG. 6. Flaky demyelination of the cerebral cortex. Dilated perivascular spaces in the gyral core. Kultschitsky-Pal $\times 8$. 


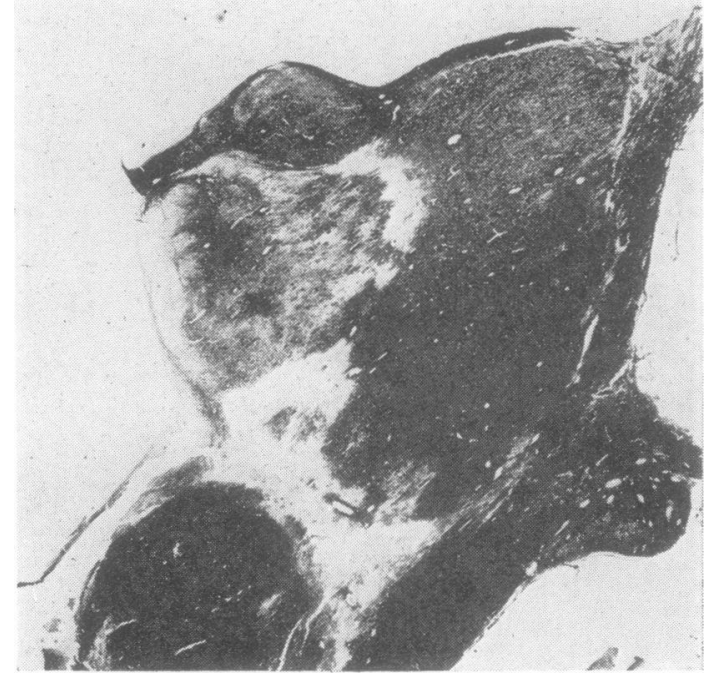

FIG. 7a. Right thalamus showing patches of myelin loss (cf. Fig. 4). Kultschitsky-Pal $\times 3 \cdot 5$.

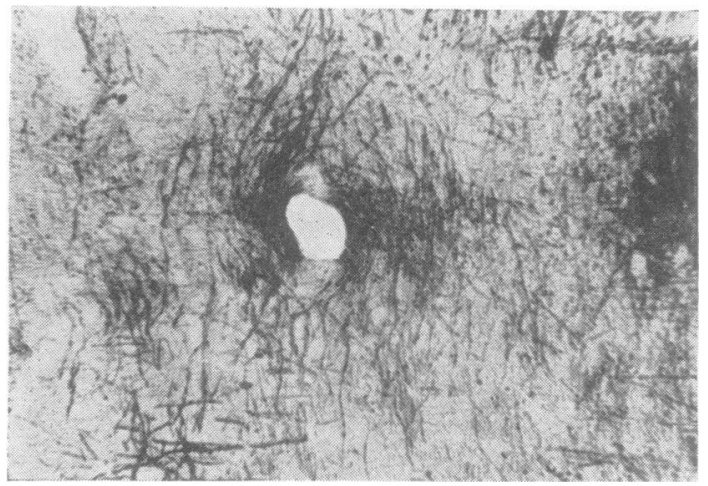

FIG. 7b. Perivascular myelin island in a patch of demyelination in the thalamus. Kultschitsky-Pal $\times 54$.

less affected and at the level of the decussation of the pyramids appeared normal.

Cerebellum Myelination was normal except for some small foci near the dentate nuclei and for centrally placed demyelination of parts of several gyral cores in the vermis and lateral lobes (Fig. 9).

Gliosis In the centrum ovale there was a diffuse and mild fibrous gliosis which became rather denser in some of the areas of more obvious myelin defect. The foci of demyelination in the thalamus and in the grey matter of the cortex, however, did not contain demonstrable glial fibrils. In the cerebellum fibrous gliosis was confined to the white

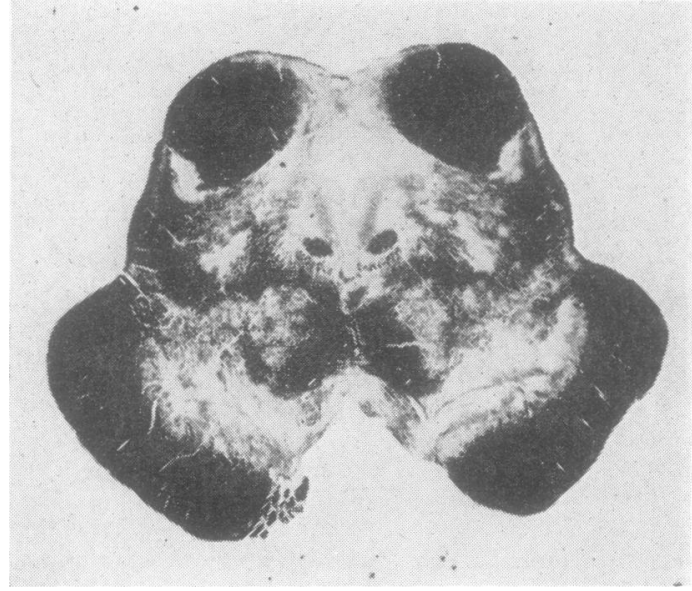

FIG. 8a. Midbrain showing symmetrical areas of demyelination in the tegmentum. Kultschitsky-Pal $\times 3 \cdot 2$.

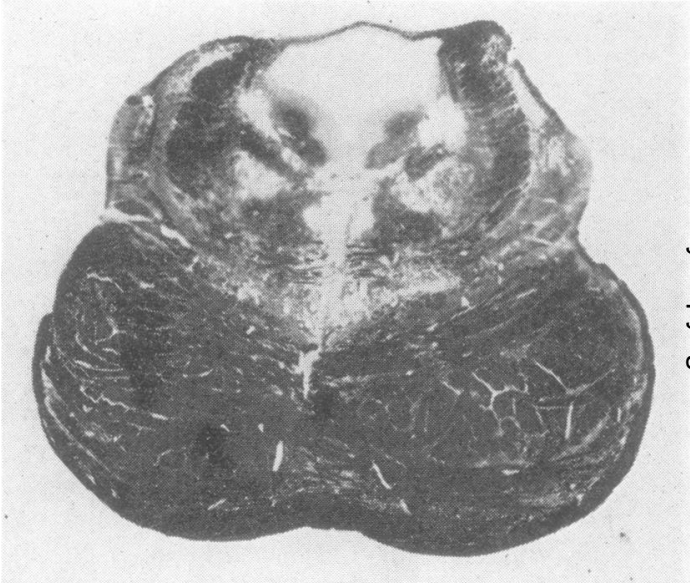

FIG. 8b. Pons showing symmetrical patches of demyelination in the tegmentum. Kultschitsky-Pal $\times 3.9$.

matter and tended to be diffuse, no differences being seen in corresponding sections between demyelinated and well-myelinated gyral cores. In the brain-stem the patchily demyelinated tegmentum contained almost no glial fibrils except in areas adjoining the ventricle.

Lipid The cerebral and cerebellar white matter contained scanty patches of microglial cells containing bright red sudanophil lipid (Fig. 10). Similar lipid was sometimes seen in the perivascular spaces, particularly in those showing marked dilatation. A doubly refractile component was occasionally present and many of the phagocytes stained positively with Marchi's method. 
Sudanophil leucodystrophy: a study of inter-sib variation in the form taken by the demyelinating process 79

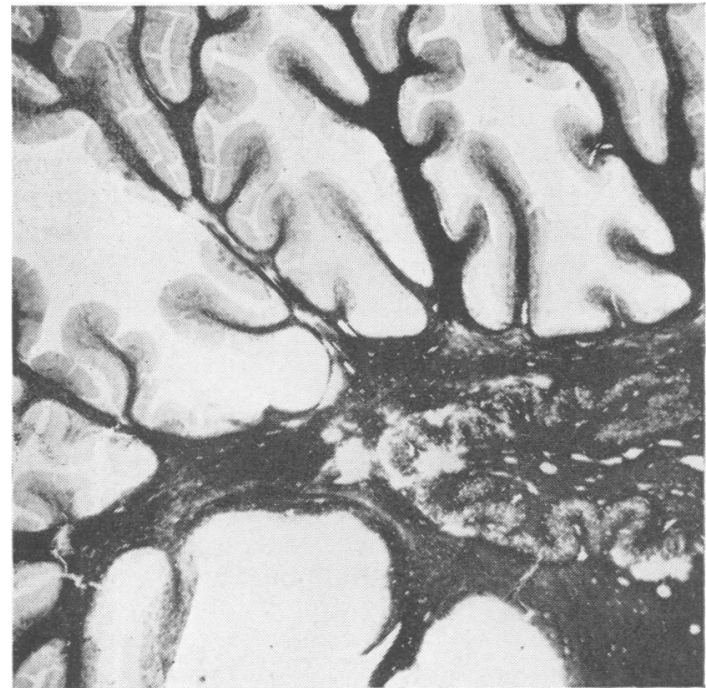

FIG. 9. Cerebellum showing patchy demyelination in the white matter. Kultschitsky-Pal $\times 4$.

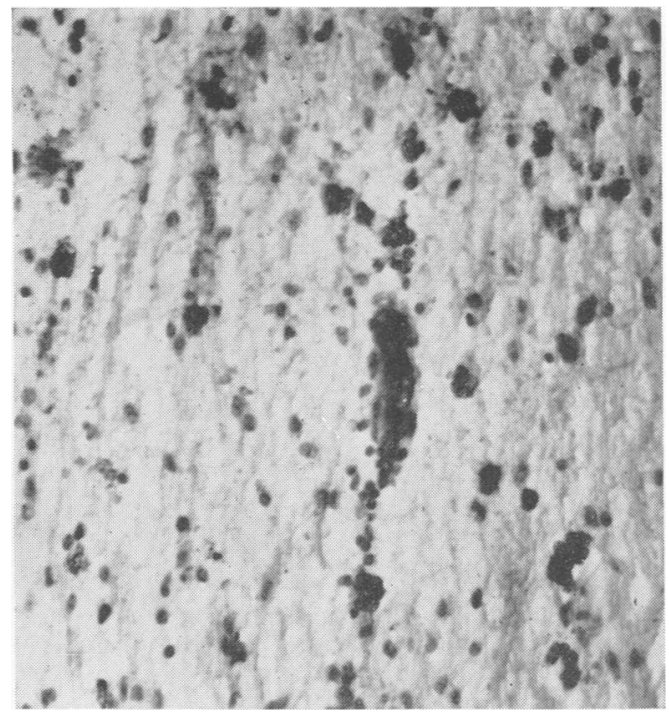

FIG. 10. Sudanophil lipid in the centrum ovale. Scharlach $R$. and haematoxylin $\times 200$.

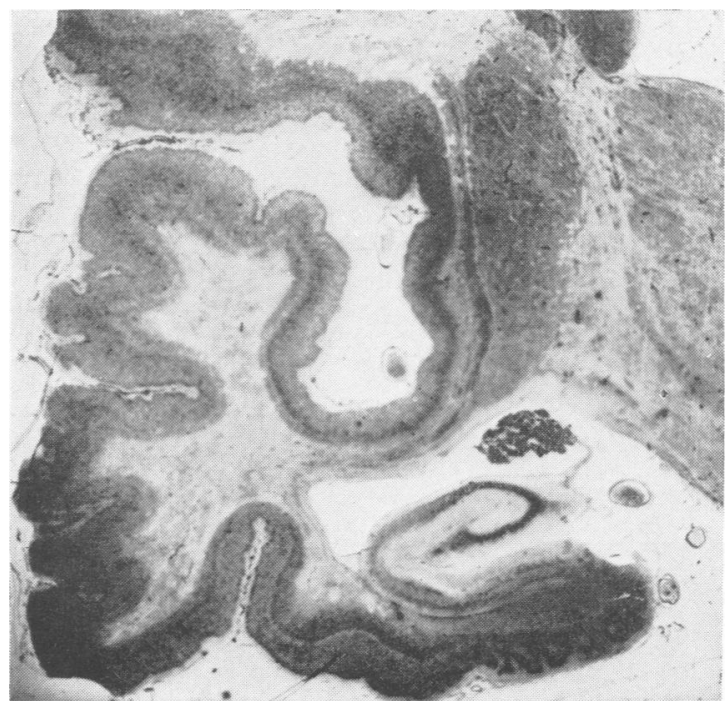

FIG. 11

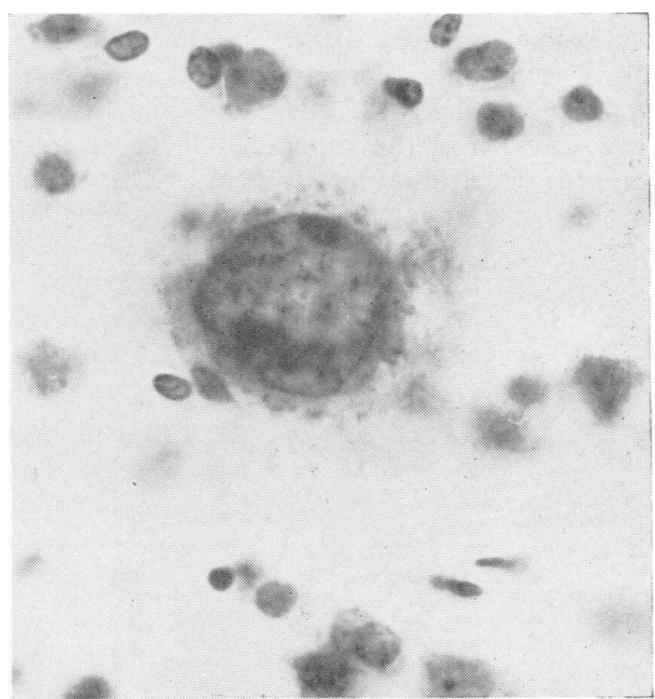

FIG. 12

FIG. 11. Coronal section of left temporal lobe showing microgyric malformation and absence of the dentate fascia in the cornu Ammonis. Carbol azure $\times 3$.

FIG. 12. Type of giant astrocytic nucleus found throughout the cerebral cortex. Carbol azure $\times 650$. 


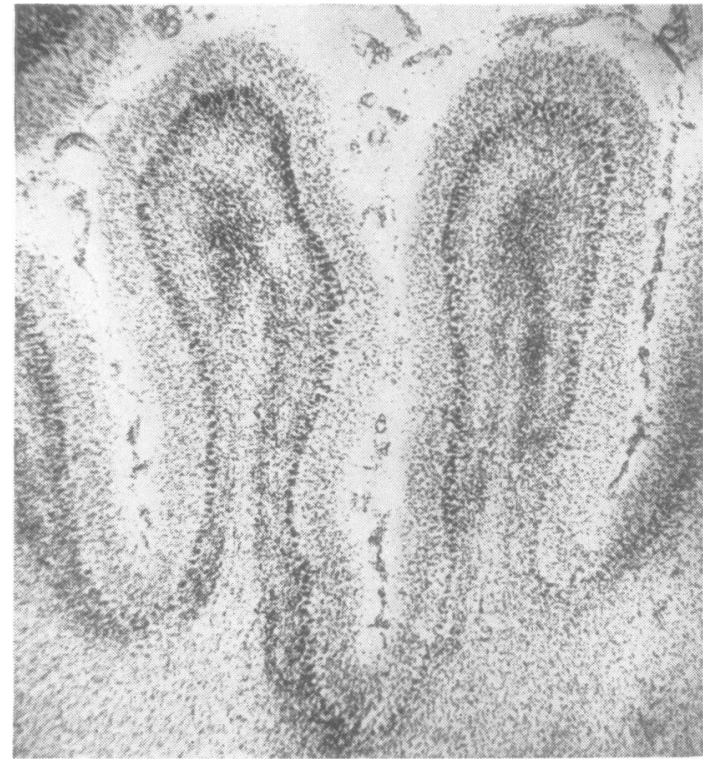

FIG. 13. Cerebellum showing atrophy of the granular layer and preservation of Purkinje cells. Carbol azure $\times 36$.

CHANGES IN GREY MATTER The thickness of the cortex in the malformed gyri showed considerable variation and was often clearly pachygyric with strands or islands of heterotopic cells forming an indistinct boundary with the white matter. In some areas, as in the temporal lobes, a suggestion of micropolygyria was given by the presence of irregularities in the superficial layer of the cortex and the penetration into the grey matter of acellular strips representing the undivided molecular layer (Fig. 11).

A peculiar finding throughout the cerebral cortex was the presence of scanty, very large nuclei of $z$ astrocytic type surrounded by a narrow rind of $\mathscr{Q}$ cytoplasm (Fig. 12). These nuclei resembled the Alzheimer I cells of Wilson's disease. Sometimes, two rather smaller nuclei were contained in the same cytoplasmic envelope and here and there clusters of ${ }_{\infty}^{0}$ much smaller astrocytic nuclei were seen. No nuclei $\lesssim$ of Alzheimer type 2 were found.

In both cornua Ammonis the dentate fascia was absent and the pyramidal cell band incompletely rolled up. There was no sectorial neuronal loss $\stackrel{\sim}{\rightarrow}$ suggestive of an anoxic process.

The cerebellar cortex showed a marked reduction $\frac{}{0}$ in the density of the granular layer especially in its superficial parts (Fig. 13). The Purkinje cells were $\stackrel{\Phi}{\varnothing}$ well preserved. No defect was seen in the fibre systems of the cortex and the Purkinje dendrites showed no swellings.

CHEMISTRY The brain had been in formal saline for two weeks before analysis, which was made by methods previously used in this laboratory (Tingey and Edgar, 1963). The results are shown in the $\omega$ Table, in which comparisons are made with the findings in the previously reported younger brothes of G.P.W. (Norman et al., 1962).

The chemical findings in the white matter A.R.W. (with the exception of sphingomyeling reflected the much better overall myelination and the far fewer fat granule cells compared with the brain of the brother. The substances showing marked increase over normal were common to bo cases and their values would be appropriate to ?a much younger individual. A point of interest was the reduced lipid hexosamine compared with the value in the other sib and this level cannot be regarded as sufficiently high to be suggestive of a leucodystrophy.

TABLE

VALUES OF CHEMICAL BRAIN CONSTITUENTS ${ }^{1}$

\begin{tabular}{|c|c|c|c|c|c|c|}
\hline \multirow[b]{2}{*}{ Brain Constituent } & \multicolumn{3}{|c|}{ White Matter } & \multicolumn{3}{|c|}{ Cerebral Cortex } \\
\hline & Normal & Case A.R.W. & Case G.P.W. & Normal & Case A.R.W. & Case G.P.W. \\
\hline Total lipid & $62 \cdot 0$ & $46 \cdot 3$ & $35 \cdot 6$ & $37 \cdot 0$ & $43 \cdot 4$ & $30 \cdot 0$ \\
\hline Total lipid hexose & $3 \cdot 72$ & 1.87 & 1.06 & 1.06 & 0.94 & 0.89 \\
\hline Neutral hexose & $2 \cdot 00$ & 0.80 & $0 \cdot 17$ & 0.40 & 0.26 & 0.20 \\
\hline Lipid hexosamine & 0.045 & $0 \cdot C 69$ & $0 \cdot 116$ & $0 \cdot 146$ & $0 \cdot 148$ & 0.210 \\
\hline Neuraminic acid & 0.058 & $0 \cdot 243$ & $0 \cdot 392$ & 0.409 & 0.402 & 0.446 \\
\hline Residue hexosamine & 0.195 & 0.401 & 0.479 & 0.485 & 0.512 & 0.540 \\
\hline Cholesterol free & $14 \cdot 0$ & $8 \cdot 8$ & $4 \cdot 0$ & $5 \cdot 8$ & $5 \cdot 4$ & 3.0 \\
\hline Cholesterol ester & Nil & 0.4 & 3.4 & 0.2 & $\mathrm{Nil}$ & 0.3 \\
\hline Total phospholipid & $22 \cdot 9$ & 180 & $11 \cdot 0$ & $19 \cdot 8$ & $18 \cdot 3$ & $15 \cdot 2$ \\
\hline Lecithin & $6 \cdot 3$ & $9 \cdot 8$ & 6.7 & 6.0 & $10 \cdot 8$ & $7 \cdot 9$ \\
\hline Sphingomyelin & $2 \cdot 6$ & $2 \cdot 3$ & $2 \cdot 6$ & $2 \cdot 1$ & 2.9 & 1.0 \\
\hline Cephalin & $12 \cdot 2$ & $5 \cdot 9$ & $7 \cdot 1$ & 10.5 & $4 \cdot 6$ & $12 \cdot 3$ \\
\hline Water & $71 \cdot 6$ & $84 \cdot 6$ & $81 \cdot 8$ & $84 \cdot 7$ & $87 \cdot 4$ & $89 \cdot 3$ \\
\hline
\end{tabular}

${ }^{1}$ All values (except water) in $\mathrm{g} . / 100 \mathrm{~g}$. of dry tissue 
The cerebral cortex showed little abnormality except for the low neutral hexose (cerebroside) and the neonatal level of lecithin.

\section{DISCUSSION}

CHANGES IN THE WHITE MATTER There were striking differences between the form taken by the demyelinating process in this brain and in the brother's. A close resemblance between the two was only seen in parts of the frontal lobe where the myelin pallor was diffuse (Fig. 3). Elsewhere, in the present case, a new element was introduced by the focal, often roughly symmetrical, patches of severe demyelination. Except for the preservation of axis cylinders these patches had no feature in common with plaques of multiple sclerosis. Their margins were ill-defined and they sometimes contained perivascular myelinated fibres. Fibrous gliosis was either absent or not sufficiently intense to give more than a vague suggestion of the localization of the focus. Fat granule cells were scanty or absent and there was none of the later products of myelin degradation. We mention these points because some authors still regard Schilder's disease (and its transitional form showing plaques similar to those of multiple sclerosis) as synonymous with sudanophil leucodystrophy. Certainly Schilder's disease (Schilder, 1912), as defined by Poser and van Bogaert (1956), could not be confused with the present condition.

When patches of myelin loss occurred in close proximity, as in the cerebellum and the tegmentum of the brain-stem, the appearance of discontinuous demyelination was given (as in so-called 'PelizaeusMerzbacher disease'), but it was especially in parts of the malformed cerebral cortex that a closely-set, flaky type of myelin loss was most obvious. In this situation the unusual density of the remaining myelinated fibres was probably a feature of the malformation, since we have seen diffuse 'hypermyelination' of the cerebral cortex in cases of micropolygyria which were unassociated with leucodystrophy or other destructive process.

Changes of the type just described were not observed in the brother's brain in which the demyelination was diffuse in the centrum ovale, while in the cerebellum and brain-stem there was a less marked but nevertheless obvious general reduction in the intensity of myelin staining. In the brother's brain it is unlikely that an acute phase of the demyelinating process had obliterated previously existing focal lesions because the abundant fat granule cells which were present in the white matter were evenly distributed and showed no suggestion of a patchy localization.

The conclusion may be drawn that these seem- ingly distinctive forms of demyelination, whether flaky or diffuse, may be alternative expressions of a single genetic defect. In their analysis of the recorded cases of 'Pelizaeus-Merzbacher' disease Diezel and Huth (1963) have pointed out that the distinguishing pathological feature shared in common is a flaky type of myelin loss. The present case could, therefore, well be classified as an example of this 'disease', whereas another name would have to be found for the brother's condition, for example, 'diffuse sudanophil leucodystrophy'. It follows from this that the definition of Pelizaeus-Merzbacher disease based on this single pathological criterion of discontinuous demyelination ('myelin islands') becomes even more inadequate than previous studies have already suggested (Norman, Tingey, Harvey, and Gregory, 1966). If the eponym is to be perpetuated (and it is probably too firmly established to be abandoned), it can properly be used either to denote a purely clinical syndrome, as advocated by Zeman, Demyer, and Falls (1964), or to denote a morphological type of sudanophil leucodystrophy rather than a separate nosological entity.

OTHER FEATURES The presence of pachygyria in both sibs confirms the conclusion reached in a previous paper that prenatal malformation of the brain may be an early expression of the abnormal gene responsible for the leucodystrophy (Norman et al., 1966). Another inherited malformation was the selective aplasia of the dentate fascia, for the same abnormality was also found on re-examining the brother's brain. This phenomenon has not, to our knowledge, been reported before and it has not been found in any of our other specimens of micro- or pachygyria.

Atrophy of the granular layer of the cerebellum was also present in both sibs and is not uncommon in sudanophil or metachromatic leucodystrophy.

The large astrocytic nuclei in the cerebral cortex were peculiar to the present case. Apparently similar cells have been described in familial spongy degeneration of the white matter (van Bogaert and Bertrand, 1949) and we have seen nuclei of this type in an unclassified case of a child of 5 years with cavitation in parts of the centrum ovale. Bischoff (1961) has also described large 'dysplastic' glial nuclei in a familial condition showing cavitation of the white matter of unknown cause. No explanation can be given of this rare finding but its association with disease of the white matter is evident.

\section{SUMMARY}

The brain of an 11-year-old spastic and microcephalic girl showed pachygyria, cerebellar atrophy of the granular layer, and partial demyelination in 
the centrum ovale, cerebellar white matter, and brain-stem. These changes have been compared with those previously reported in the patient's younger brother who closely resembled his sister clinically. In the present case the demyelination was seen mainly as flaky, discontinuous loss of myelin sheaths in parts of the cerebral cortex and cerebellum and as small, usually symmetrically placed and ill-demarcated patches of myelin loss in the centrum ovale, thalamus, and brain-stem. These focal lesions had not been found in the brother's brain in which the demyelination was diffuse. The scanty sudanophil lipid in the degenerated areas was also in contrast to the abundant breakdown products of similar type in the brother. In both brains, axis cylinders were well preserved. Chemically there were more myelin lipids and less lipid hexosamine in the sister's brain. This inter-sib variation in the form taken by the demyelinating process shows that the same genetic abnormality can produce either a diffuse or a discontinuous type of myelin loss. The latter is not, therefore, by itself an adequate criterion for classifying 'Pelizaeus-Merzbacher disease' as a nosological entity and thus separating it from the main group of sudanophil leucodystrophies.

\section{REFERENCES}

Bischoff, A. (1961). Familiäres Syndrom des Säuglingsalters mit Myoklonie (Blitz-Nick-Krämpfen), Hypsarythmie und schwerem psychomotorischem Entwicklungsrückstand. Psychiat. Neurol. Neurochin. (Amst.), 64, 133-148.

Diezel, P. B., and Huth, K. (1963). Pelizaeus-Merzbachersche Erkrankung mit familiärem Befall. Dtsch. Z. Nervenheilk., 184, 264-287.

Norman, R. M. Tingey, A. H., Harvey, P. W., and Gregory, A. M. (1966). Pelizaeus-Merzbacher disease: a form of sudanophil leucodystrophy. J. Neurol. Neurosurg. Psychiat., 29, 521-529.

- Valentine, J. C., and Danby, T. A. (1962). Sudanophil leucodystrophy in a pachygyric brain. Ibid., 25, 363-369.

Poser, C. M., and van Bogaert, L. (1956). Natural history and evolution of the concept of Schilder's diffuse sclerosis. Acta psychiat. scand., 31, 285-331.

Schilder, P. (1912). Zur Kenntnis der sogenannten diffusen Sklerose. ڤั (Úber Encephalitis periaxialis diffusa). Z. ges. Neurol. Pyschiat., 10, 1-60.

Tingey, A. H., and Edgar, G. W. F. (1963). A contribution to the chemistry of the leucodystrophies. J. Neurochem., 10, 817-823.

van Bogaert, L., and Bertrand, I. (1949). Sur une idiotie familiale avec dégénérescence spongieuse du névraxe. Acta neurol. belg., 49, 572-587.

Zeman, W., Demyer, W., and Falls, H. F. (1964). Pelizaeus-Merzbacher disease: a study in nosology. J. Neuropath., exp. Neurol., 23, 334-354. 